\title{
Dental caries in the primary dentition of a Colombian population according to the ICDAS criteria
}

\begin{abstract}
Alexandra Saldarriaga Cadavid(a) Clara María Arango Lince(b) Marisela Cossio Jaramillo(c)
\end{abstract}

(a) DDS, MSc in Epidemiology, Assistant Professor; (b)DDS, Professor; ${ }^{(c)}$ Graduate Student in Pediatric Dentistry - Department of Pediatric Dentistry and Cariology, School of Dentistry, CES University, Colombia.

Corresponding author: Alexandra Saldarriaga Cadavid Health Science and Research Department, CES University

Calle 10 NN$^{\circ} 22-04$ El Poblado

Medellín - Colombia

E-mail: asaldarriaga@ces.edu.co

Received for publication on Jun 23, 2009 Accepted for publication on Nov 10, 2009

\begin{abstract}
This paper describes the results of a cross-sectional study conducted with a randomized sample of 447 low-income children between 2.5 and 4 years of age selected from the files of a health institution in Medellin, Colombia. The patients were examined in 2007 using the modified criteria of the International Caries Detection and Assessment System (ICDAS); the first caries code was not used. Clinical examination was carried out by three examiners previously trained in the ICDAS. The inter-examiner agreement was rated as good (kappa $0.73-0.82$ ). The prevalence of untreated caries was $74.7 \%$ (335) with a mean of $9.7 \pm 9.4$ affected surfaces. The prevalence of caries (treated and untreated) was $74.9 \%$ (335). The mean dmf-s was 7.6 \pm 9.7 . The prevalence of non-cavitated lesions on at least one tooth surface was $73.4 \%$. Cavitated lesions were more frequent on smooth surfaces than on occlusal surfaces (respectively $64.7 \%$ and $46.8 \%$; p value $<0.001)$. Only $25.1 \%(112.5)$ of the children had no clinical signs of caries according to the ICDAS criteria. It was concluded that dental caries is a highly prevalent condition in this Colombian population, the main contributor being non-cavitated lesions. There was an association between caries and oral hygiene practices, such as the amount of toothpaste used, and also between caries and the occurrence of a previous dental visit ( $\mathrm{p}$ value $<0.00$ ). Eating habits constituted no statistically significant association.
\end{abstract}

Descriptors: Dental caries; Prevalence; Dentition, primary.

\section{Introduction}

During the last decades, there have been changes not only in the prevalence of dental caries, but also in the distribution and pattern of the disease. ${ }^{1}$ Oral health inequalities have emerged as a major public health issue as low income and socially disadvantaged groups experience disproportionately high levels of oral disease. ${ }^{2}$ Detection of lesions during the early non-cavitated stage among these groups is now an important challenge in the diagnostic process. Given the dynamic nature of dental caries, it is possible to arrest and control disease progression through the remineralization of lesions before they progress to a cavity. ${ }^{3}$

When white spot lesion detection as well as early identification of non-cavitated lesions are included in the clinical diagnostic process, the prevention of primary dental caries and a timely non-operative treatment become possible, thus effectively averting the progression towards cavi- 
tated lesions and allowing a short-term control of the disease, with long-term effects. It is currently well known that a single preventive measure in itself is not enough to reduce dental caries; it is therefore best combined with other preventive and curative actions. ${ }^{4,5}$ According to The World Health Organization (WHO), a dental health program should include dental education in conjunction with other activities related to prevention, restoration and emergency attention. ${ }^{6,7,8}$

Preventive strategies must be applied according to current diagnostic criteria that include non-cavitated lesions, such as the International Dental Caries Detection and Assessment System (ICDAS). ${ }^{9}$

In Colombia, the dental health of preschool children has been neglected in official health policies, since it is not considered an important part of their well-being or general health status. Previous studies, including the last national survey of dental health (ENSAB III), ${ }^{10}$ have excluded this age group. Therefore, the prevalence of dental caries in Colombian children under 5 years of age remains unknown. Some regional studies performed during the last decade have shown a prevalence ranging between $11.3 \%$ and $97 \%$, including non-cavitated lesions. ${ }^{11,12,13}$ However, there is no dental caries primary preventive program for children between 1 and 5 years of age, and the adopted criteria are not standardized.

The aim of this paper was thus to describe the dental caries situation of a Colombian pediatric population using the new diagnostic practices and criteria of the International Dental Caries Detection and Assessment System (ICDAS). ${ }^{9}$

\section{Materials and Methods}

A total of 447 children living in the urban area of Medellin, Colombia, who were between 2.5 and 4.0 years of age, were examined in a cross-sectional study. The inclusion criteria were fully erupted primary dentition, absence of systemic involvement, and low socioeconomic status. This age group was defined to meet the requirement of a complete deciduous formula. Since there were no references on the prevalence of caries in this age group at the time of the study, the sample size was estimated to have a variability of $50 \%$, a sample error of $5 \%$ and a reliability of $95 \%$, thus leading to a sample size of 383 subjects, adjusting for non-response or losses of $15 \%$.

A questionnaire was applied to the parents or legal guardians of the children to explore the variables related to oral hygiene, eating habits, educational level, motivation for first dental appointment and systemic medication.

\section{Clinical examination}

In this study, the presence of caries was assessed using the International Caries Detection and Assessment System (ICDAS). Dental examination was performed by three examiners. The reliability in classifying tooth surfaces using the ICDAS was rated as good, with intra-examiner Kappa coefficients ranging between 0.75 and 0.85; Kappa coefficients for the inter-examiner reliabilities ranged between 0.73 and 0.82 . The ICDAS criteria applied on all tooth surfaces are described in Table 1 . Code 1 was not used in this study.

Professional oral cleaning was performed prior to clinical examination. An $11.5 \mathrm{~B}$ WHO periodontal probe, an air syringe and adequate illumination were used by the examiner during clinical evaluation. A signed informed consent was obtained from parents prior to examination and study participation. The study was approved by the Ethical Research Committees of the institutions involved.

On the first appointment, the children were accompanied by their parents. During the appointment, information regarding oral health instructions and dietary counseling were given, and their specific dental caries risk factors were determined.

\section{Data analysis}

The frequency and severity of the disease were analyzed based on a proportional distribution of diagnostic categories. To explore the relation between dental caries and issues related to behavior, a bivariate logistic regression analysis and the chi-square test were performed. The threshold of significance was $\leq .05$.

The Intercooled Stata 9 statistical software for Windows (Stata Corp. LP, College Station, TX, 
Table 1 - Classification of carious status based on the International Caries Detection and Assessment System.

\begin{tabular}{c|l}
\hline Code & \multicolumn{1}{c}{ Criteria } \\
\hline 6 & $\begin{array}{l}\text { Extensive distinct cavity with clearly visible dentin. The cavity is both deep and wide. Dentin is clearly visible on both the walls and at } \\
\text { the base. An extensive cavity involves at least half of a tooth surface, possibly reaching the pulp. }\end{array}$ \\
\hline 5 & Distinct cavity with visible dentin cavitation in opaque or discolored enamel with exposed dentin in the examiner's judgment. \\
\hline 4 & Underlying dark shadow from dentin, with or without enamel breakdown. The shadow may appear as grey, blue, or brown in color. \\
\hline 3 & Initial localized enamel breakdown, without clinically visual signs of dentinal involvement. \\
\hline 2 & $\begin{array}{l}\text { Distinct visual change in enamel. When wet, there is a carious opacity (white spot lesion) and / or brown carious discoloration } \\
\text { which is wider than the natural fissure / pit. }\end{array}$ \\
\hline 0 & Not included in this study. \\
\hline
\end{tabular}

Extracted from Ismail Al, Sohn W, Tellez M, Amaya A, Sen A, Hasson H, Pitts NB.?

USA) was used to perform the analysis.

\section{Results}

A total of 447 children with an average age of $2.8 \pm 0.48$ years (ranging from 2.5 to 4 years) were examined. The distribution between genders was 217 females $(48.5 \%)$ and 230 males $(51.5 \%)$. The prevalence of untreated dental caries was $74.9 \%$ (335), with a specific mean of affected surfaces by cavitated or non-cavitated lesions of $9.7 \pm 9.4$ (Table 2).

The prevalence of dental caries (treated and untreated) was $74.9 \%$ (335), and the mean dmf$\mathrm{s}$ was $7.7 \pm 9.7$. The mean $\mathrm{dmf}$ components were: $92.1 \pm 10.04$ sound surfaces, $0.38 \pm 1.8$ filled surfaces, and 0.01 missing teeth. The frequency of filled and missing surfaces due to caries was very low, $8.5 \%$ and $0.4 \%$ respectively; this finding was related to the children's age. The distribution according to lesion severity is shown in Table 2.

The severity of cavitated lesions according to the ICDAS, classified as codes 5 and 6 (enamel and dentine), had a prevalence of $19.7 \%$ and a mean of $1.3 \pm 3.8$ affected surfaces. The children classified with these codes presented severe dental caries lesions, with cavities that required operative treatment.

The early non-cavitated caries lesions alone had a general prevalence of $73.4 \%$ in children, with at least one affected surface. Analysis of the non-cavitated lesion distribution between smooth $(64.7 \%)$ and occlusal (pits/fissures) surfaces $(46.8 \%)$ revealed that this type of lesion was significantly more frequent on smooth surfaces than on occlusal surfaces $\left(\mathrm{p}=0.0000 / \mathrm{Chi}^{2}=29.01\right)$. More than a third of the sample $(37.8 \%, 169)$ had both types of lesions, smooth and occlusal.

Dental caries increased with age $(\mathrm{p}=0.0262)$, but no significant statistical differences were found for gender. Only $25.1 \%$ (112.5) of the children were caries-free, with no clinical signs of caries at the level assessed by the ICDAS, and were not affected by filled or missing surfaces. The most severely affected teeth were the lower second primary molars.

The bivariate analysis did not show any significant relationships between the prevalence of early childhood caries (ECC) and gender, age of onset of oral hygiene habits, frequency of tooth brushing and whether or not it was supervised, dental toothpaste used, eating habits, snacking frequency, breast-feeding, bottle-feeding, medication, day care institution attendance and the parent's educational level ( $\mathrm{p}$ value $\geq 0.05$ ). A statistically significant association between dental caries and the occurrence of a previous dental visit and the motive for a previous visit (check-up, caries/pain, trauma, etc.) was found, with a $p$ value of 0.0010 and 0.0014 , respectively.

To explore the association between these variables and the development of early childhood caries, a logistic regression model was applied. The analysis found a statistically significant association only between the presence of caries and age, occurrence of a previous dental visit $(\mathrm{p}$ value $=0.0014$ ) and amount of dental toothpaste, with a $\mathrm{p}$ value of 
Table 2 - General prevalence situation and severity of dental caries.

\begin{tabular}{|c|c|c|c|c|c|c|c|c|c|c|}
\hline & & \multirow{3}{*}{$\begin{array}{c}\text { Prevalence } \\
(\%)\end{array}$} & \multicolumn{4}{|c|}{ Including sound surfaces } & \multicolumn{4}{|c|}{ Not including sound surfaces } \\
\hline & & & \multirow{2}{*}{$\bar{X} \pm S D$} & \multicolumn{3}{|c|}{ Percentiles } & \multirow{2}{*}{$\bar{X} \pm S D$} & \multicolumn{3}{|c|}{ Percentiles } \\
\hline & & & & 25 & 50 & 75 & & 25 & 50 & 75 \\
\hline \multirow{3}{*}{ Untreated } & $d_{5-6} \geq 1$ & 19.7 & $1 \pm 3.0$ & 0 & 0 & 0 & $5 \pm 5.1$ & 1 & 4 & 7 \\
\hline & $d_{3-6} \geq 1$ & 31.3 & $1.5 \pm 3.8$ & 0 & 0 & 1 & $5 \pm 5.3$ & 1 & 3 & 7 \\
\hline & $d_{2-6} \geq 1$ & 74.7 & $7.3 \pm 9.1$ & 0 & 3 & 12 & $9.7 \pm 9.4$ & 2 & 6 & 15 \\
\hline \multirow{3}{*}{$\begin{array}{l}\text { Untreated and } \\
\text { treated }\end{array}$} & $\mathrm{d}_{5-6 \mathrm{mfs}} \geq 1$ & 22.7 & $1.3 \pm 3.8$ & 0 & 0 & 0 & $5.8 \pm 6.1$ & 2 & 4 & 7 \\
\hline & $d_{3-6 \mathrm{mfs}} \geq 1$ & 34.2 & $1.9 \pm 4.6$ & 0 & 0 & 2 & $5.7 \pm 6.4$ & 1 & 3 & 7 \\
\hline & $\mathrm{d}_{2-6 \mathrm{mfs}} \geq 1$ & 74.9 & $7.7 \pm 9.7$ & 0 & 3.5 & 12 & $10.2 \pm 10$ & 2.5 & 6.5 & 16 \\
\hline \multirow{3}{*}{$\begin{array}{l}\text { Non-cavitated } \\
\text { lesion }\end{array}$} & $d_{2} \geq 1$ & 73.4 & $5.7 \pm 7.1$ & 0 & 3 & 9 & $7.7 \pm 7.2$ & 2 & 5 & 12 \\
\hline & $d_{2}$ sts $\geq 1$ & 64.7 & $4.4 \pm 5.9$ & 0 & 2 & 7 & $6.8 \pm 6.1$ & 2 & 4 & 10 \\
\hline & $d_{2}$ ots $\geq 1$ & 46.8 & $1.3 \pm 1.8$ & 0 & 0 & 2 & $2.7 \pm 1.7$ & 1 & 2 & 4 \\
\hline
\end{tabular}

sts $=$ Smooth tooth surfaces. ots $=$ Occlusal tooth surfaces. $\mathrm{mfs}=$ missing, filled surfaces

Table 3 - Logistic regression analysis.

\begin{tabular}{c|c|c|c}
\hline \multirow{2}{*}{ Variables } & \multirow{2}{*}{ OR } & \multicolumn{2}{|c}{$95 \% \mathrm{Cl}$} \\
\cline { 3 - 4 } & & Lower & Upper \\
\hline Age & 2.007 & 1.216 & 3.314 \\
\hline Previous dental visit & 2.159 & 1.279 & 3.647 \\
\hline Toothpaste quantity & 0.533 & 0.323 & 0.879 \\
\hline
\end{tabular}

0.0065 (Table 3).

\section{Discussion}

The results revealed severe early childhood caries at the $\mathrm{d} 2 \mathrm{~d} 3$ level in $332(74.3 \%)$ children, and at the $\mathrm{d} 5 \mathrm{~d} 6$ level in $88(19.7 \%)$ children. Only a quarter of the children were dental caries-free. Even though there was a significant prevalence of localized enamel breakdown due to caries (Code 3), the greatest prevalence was due to non-cavitated lesions (Code 2). The initial chemical change on surface enamel is considered the earliest sign of dental caries. This early subsurface lesion should not be allowed to progress. Cavity formation can be prevented by controlling the natural process of caries. It is currently well known that any lesion at any stage of progression can be arrested. ${ }^{14,15}$ The high percentage of non-cavitated lesions found in this study indicates that there is an elevated possibility of progression toward cavity unless timely attention and monitor- ing is provided. In addition, this finding suggests that this type of lesion could go undiagnosed, because the current criteria system used for the clinical detection of caries, which includes non-cavitated lesions, has not been widely recognized. Dental caries were measured with the criteria of the International Caries Detection and Assessment System (ICDAS). Since it was difficult to differentiate between codes 2 and 1 , code 1 was not considered. Although the examiners took special care to avoid misdiagnosis, a misclassification of code 1 as code 2 could have occurred. ${ }^{9,15,16}$

The high prevalence of untreated dental caries found in the present study $\left(74.7 \%-\mathrm{d}_{2-6 \geq} 1\right)$ shows that the objective of reducing the proportion of young children between 2-4 years old with dental caries in their primary teeth to $11 \%$, as the "Healthy People 2010 - Oral Health" proposes, ${ }^{17}$ is far from being achieved.

The results presented here, as well as in other dental caries reports, show how this disease continues to be very frequent in this age group. In Colombian children, as in other countries, the disease behaves differently when compared with other studies, being more prevalent at the $d_{2-6}$ level than at the $d_{5-6}$ level. Even though there are no previously published results using the ICDAS criteria in Colombia or Latin America, data using the dmf traditional criteria 
reported a dental caries prevalence of $13.5 \%$ in the same age group in low-income children, and $21.9 \%$ in another group between 0 and 6 years of age. ${ }^{18,19}$ When non-cavitated lesions are included in the different socio-economic groups, the untreated caries prevalence rises to $35-97 \% .{ }^{12,13,20,21}$ These results can also be compared with some early childhood caries prevalence data in this age group, encountered during the last five years in Canada, ranging from 57 to $98 \% .^{22}$ There are some other studies reporting the use of the ICDAS criteria among 1- to 5-yearold children in a population from Detroit, ${ }^{23}$ with an early childhood caries prevalence (ECC) ranging from $30 \%$ to $44 \%$, and a caries-free finding of $17 \%$. This study corroborates the importance of using diagnostic criteria similar to that of the ICDAS.

The high frequency of non-cavitated lesions reported in the present study contrasts with other reports according to which these lesions are reported as most prevalent in developed countries. ${ }^{1,11}$ However, it also confirms other findings, namely that caries increases with age, that smooth surfaces are the most affected, and that the disease appears early in life. ${ }^{24,25}$ The present study adds to the evidence of a global change in the clinical onset and distribution of dental caries in low-income populations.

In the present study, no significant relationships between prevalence of dental caries and gender were found, similarly to the findings of Schroth et al. $(2007)^{25}$ and differing from those of Ismail et al. $(2008)^{24}$, who found gender to be a dental caries predictor, with boys being more affected than girls. This study further suggests that the amount of dental toothpaste could have an impact on the efficacy of prevention, and supports the controversy around the question of whether a small amount of dental toothpaste could be used without compromising efficacy. It was also found that even the children who had previously gone to a dental visit still presented a high prevalence of dental caries. The lack of association between dental caries and eating habits found in this study could be related to the inconsistent eating patterns of this study group.

In Colombia, the government actions to impact dental health have poor coverage and are directed to school children (with ages over 6 years), with some deficiencies in early childhood programs. The current preventive dental health policy has many inconsistencies and deficiencies regarding access, efficacy, and continuity of the services and special programs for the infant population. ${ }^{26}$ The inclusion of infants and young children in the prevention programs could decrease the risk for dental caries and minimize the need for invasive and painful treatment procedures.

Our findings highlight the need for a policy revision in order to include early childhood in dental preventive strategies, and to define appropriate preventive approaches, considering the high prevalence of dental caries in this age group, which could lead to dental caries in adults.

\section{Conclusions}

Non-cavitated caries lesions are highly prevalent in the Colombian population studied. These results confirm that the disease pattern has changed and suggest the need to redirect dental health programs towards early detection of dental caries using new criteria for diagnosis and assessment, as well as non-operative/preventive care and treatment by preparing the dental team both at the private and the public levels. ${ }^{1,15,16}$

The high prevalence of non-cavitated lesions on smooth surfaces relative to pits and fissures indicates that caries are highly active and appear early in life.

Caries risk is individual and evident, and considering that there are some groups under permanent risk for the disease, health institutions should dedicate proper attention to these age groups. The design and implementation of preventive programs and the adoption of homogeneous diagnostic criteria for preschoolers should be a priority. The present study also corroborates the importance of using diagnostic criteria similar to that of the ICDAS.

\section{Acknowledgements}

The authors gratefully acknowledge Dr. Gonzalo Alvarez for his support to the statistical analysis. 


\section{References}

1. Diagnosis and management of dental caries throughout life. National Institutes of Health Consensus Development Conference statement, March 26-28, 2001. J Dent Educ. 2001 Oct;65(10):1162-8.

2. Petersen PE. The World Oral health Report 2003: continuous improvement of oral health in the $21^{\text {st }}$ Century- the approach of the WHO global oral Health Program. Community Dent Oral Epidemiol. 2003;31 (Suppl 1):3-24.

3. Scottish Intercollegiate Guidelines Network. Prevention and management of Dental Decay in the pre-school child: a national clinical guideline [Internet]. Edinburg: Scottish Intercollegiate Guidelines Network; 2005 Nov [cited 2009 Oct 10]. 44p. Available from: http://www.sign.ac.uk/pdf/sign83. $p d f$.

4. Axelsson S, Soder B, Nordenram G, Petersson LG, Dalhgren $\mathrm{H}$, Norlund A et al. Effect of combined caries-preventive methods: a systematic review of controlled clinical trials. Acta Odontol Scand. 2004;62(3):163-9.

5. Kay EJ, Locker D. Is dental health education effective? A Systematic review of current evidence. Community Dent Oral Epidemiol.1996 Aug;24(4):231-5.

6. Vachirarojpisan T, Shinada K, Kawaguchi Y. The process and outcome of a program for preventing early childhood caries in Thailand. Community Dent health. 2005 Dec;22(4):253-9.

7. Davies GM, Duxbury JT, Boothman NJ, Davies RM, Blinkhorn AS. A staged intervention dental health promotion program to reduce early childhood caries. Community Dent Health. 2005;22(2):118-22.

8. Watt RG. Strategies and Approaches in Oral Disease Prevention and Health Promotion. Bull World Health Organ. 2005 Sep;83(9):711-8.

9. Ismail AI, Sohn W, Tellez M, Amaya A, Sen A, Hasson H, et al. The International Caries Detection and Assessment System (ICDAS): an Integrated System for Measuring Dental Caries. Community Dent Oral Epidemiol. 2007;35(3):170-8.

10. República de Colombia Ministerio de Salud. III Estudio Nacional de Salud Bucal-ENSAB III. Bogotá: Ministerio de Salud; 1999 (Serie Documentos Técnicos; Tomo VII)

11. Escobar G, Ortiz A, Mejía L. Caries dental en los menores de veinte años en Colombia: un problema de salud pública. Rev Fac Nac Salud Pública. 2003;21(2):107-18.

12. Gonzalez MC, Luiz JA, Fajardo MC, Gomez AD, Moreno ES, Ochoa MJ, et al. Comparison or the def Index with Nyvad's Caries Diagnostic Criteria in 3- and 4-year-old Colombian children. Pediatr Dent. 2003 Mar-Apr;25(2):132-6.
13. Franco AM, Santamaría A, Kurzer E, Castro L, Giraldo M. El menor de seis años: Situación de caries y conocimientos y prácticas de cuidado bucal de sus madres.CES Odontol. 2004;17(1):20-9.

14. Fejerskov O. Concepts of dental caries and their consequences for understanding the disease. Community Dent Oral Epidemiol. 1997 Feb;25(1):5-12.

15. Ismail AI. Visual and Visuo-tactile Detection of Dental Caries. J Dent Res. 2004;83 Spec No C:C56-C66.

16. Pitts N.B. Are we ready to move from operative to non-operative/preventive treatment of dental caries in clinical practice? Caries Res. 2004 May-Jun;38(3):294-304.

17. U.S. Department of Health and Human Services. Healthy People 2010: Understanding and improving health. Washington, DC: U.S Government Printing Office; 2000.

18. Macias M, Bustamante ZM, Camargo L, Correa P, Hernández ME. Estado de salud bucal en preescolares de nivel socioeconómico alto y medio alto. [Thesis]. [Medellin]: Universidad CES; 1998.

19. Gravina DB, Cruvinel VR, Azevedo TD, de Toledo OA, Bezerra AC. Prevalence of dental caries in children born prematurely or at full term. Braz Oral Res. 2006 Oct-Dec;20(4):353-7.

20. Santos APP, Soviero VM. Caries prevalence and risk factors among children aged 0 to 36 months. Pesqui Odontol Bras. 2002 Jul-Sep;16(3):203-8

21. Escobar-Paucar G, Ramirez-Puerta BS, Franco-Cortes AM, Tamayo-Posada AM, Castro-Aguirre JF. Experiencia de caries dental en niños de 1-5 años de bajos ingresos. Medellín Colombia. Rev CES Odontol. 2009;22(1):21-8.

22. Schoroth RJ, Moffatt ME. Determinants of early childhood caries (ECC) in a rural Manitoba Community: a pilot study. Pediatr Dent. 2005 Mar-Apr;27(2):114-20.

23. Finlayson TL, Siefert K, Ismail AI, Sohn W. Psychosocial factors and early childhood caries among low-income African -American children in Detroit. Community Dent Oral Epidemiol. 2007 Dec;35(6):439-48.

24. Ismail AI, Lim S, Sohn W, Willem JM. Determinants of early childhood caries in low-income African American young children. Pediatr Dent. 2008 Jul-Aug;30(4):289-96.

25. Schroth RJ, Cheba V. Determining the prevalence and risk factors for early chilhood caries in a community dental health clinic. Pediatr Dent. 2007 Sep-Oct;29(5):387-96.

26. Colombia. Ministerio de la Protección Social. Resolución 3577 de 2006. (Plan Nacional de Salud Bucal), Bogotá: Ministerio de protección social; 2006. 